\title{
Pregnancy outcomes after spontaneous conception with previous spontaneous abortion preceding present pregnancy
}

\author{
Shree Kant Dadheech, Meenakshi K. Bharadwaj*, Brig Aruna Menon
}

Department of Obstetrics and Gynecology, Armed Forces Medical College, Pune, Maharashtra, India

Received: 17 March 2021

Accepted: 07 June 2021

\section{*Correspondence: \\ Dr. Meenakshi K. Bharadwaj, \\ E-mail: mkb.doc@gmail.com}

Copyright: () the author(s), publisher and licensee Medip Academy. This is an open-access article distributed under the terms of the Creative Commons Attribution Non-Commercial License, which permits unrestricted non-commercial use, distribution, and reproduction in any medium, provided the original work is properly cited.

\begin{abstract}
Background: The objective of the present study was to study pregnancy outcomes in patients with Spontaneous conception with history of previous spontaneous abortion preceding present pregnancy.

Methods: A prospective study included patients with spontaneous conception with history of previous spontaneous abortion preceding present pregnancy admitted in the department of obstetrics and gynecology, command hospital, Pune between October 2018 and April 2020. The patients were booked (minimum 3 visits in antenatal outdoor clinic) or admitted for the first time as an emergency. The detailed history about previous abortions was taken and routine as well as investigations for possible etiologies of previous abortions were done. Cases with history of mid-trimester abortion were investigated for cervical incompetence. All the patients were observed for complications during present pregnancy like threatened abortion, preeclampsia, preterm labour, intrauterine death and final outcome.

Results: A total of 110 patients with history of previous spontaneous abortion were admitted, all patients were booked. Majority (51.8\%) of patients belong to the age group 25-30 years. All patients were with history of previous one abortion followed by pregnancy with spontaneous conception. The final outcomes were term live birth (86.4\%), abortion $(8.2 \%)$, preterm delivery $(5.4 \%)$, and no still birth. Caesarian section was done in $32.7 \%$ patients for various indications.

Conclusions: Previous history of spontaneous abortion is associated with adverse pregnancy outcome. There is increased risk of abortion, preterm delivery, need for caesarean sections and fetal loss in cases of previous spontaneous abortions. These complications and fetal loss can be reduced by booking the patients and giving due antenatal care.
\end{abstract}

Keywords: Spontaneous abortion, Preterm birth, Cesarean delivery, Spontaneous conception

\section{INTRODUCTION}

Spontaneous pregnancy loss is a common event, it is the most common complication of pregnancy. About $70 \%$ of human conceptions fails to achieve viability and an estimated $50 \%$ are lost before the $1^{\text {st }}$ missed menstrual period.

It is considered that chromosomal abnormality is the most common cause of spontaneous abortion. More than $50 \%$ of spontaneous abortions are related to some genetic abnormality of the embryo. ${ }^{1}$ Studies have shown that the incidence rate of spontaneous abortion increases with the increase of pregnant women's age. ${ }^{2}$

There has been a prevailing concern about spontaneous pregnancy loss/induced abortion increasing the risk of adverse outcomes in future pregnancies. Many different adverse outcomes have been linked to miscarriages, such as increased risks of preterm birth, low birth weight, SGA infants, placental complications, ectopic pregnancy and miscarriages. At present the suspected mechanisms connecting miscarriages to adverse outcomes in following pregnancies include ascending infection after impairment of the anti-microbial defense mechanism because of 
cervical trauma, mechanical trauma to the cervix leading to cervical incompetence and surgical damage to the endometrium, increasing the risk of abnormal placental implantation. ${ }^{3-8}$

Increase in the risk of abortion after a previous abortion is reported consistently, but the reported risks of recurrence differ considerably, and no generally accepted figures are available. ${ }^{9-12}$

In this study impact of spontaneous abortions on subsequent pregnancies will be observed in the form of recurrent abortion, influence of previous abortion on mode of delivery and neonatal outcomes in the form of low birth weight and stillbirth.

\section{METHODS}

The study type was prospective observational study. The study conducted from October 2018 to May 2020. The study was conducted at department of obstetrics and gynecology of command hospital, Pune.

\section{Selection criteria}

Pregnant women after spontaneous conception with history of spontaneous abortions, preceding present pregnancy, irrespective of gravidity were enrolled. Detailed history regarding previous abortion was taken and examination was done focusing on information about previous abortion all women were followed up till the postnatal period and pregnancy outcomes were charted.

\section{Ethical approval}

The ethical approval taken by the committee.

Primary and secondary objectives of the study are charted in table below. Primary objectives were term live birth, preterm live birth, spontaneous abortion whereas secondary objectives were cesarean delivery, stillbirth, placenta previa and low birth weight. Instrumental deliveries are also charted in the table.

\section{RESULTS}

A total of 110 patients with history of previous spontaneous abortion were admitted, all patients were booked. All patients were with history of previous one abortion followed by pregnancy with spontaneous conception. Most of the study population belongs to the age group of 25 to 30 years $(51.8 \%)$ followed by less than 25 years $(34.5 \%)$ and more than 30 years $(13.6 \%)$. Most of the study population were nullipara $(68.2 \%)$ followed by para $1(28.2 \%)$ and para $2(3.6 \%)$.

Most of the study population had 38 to 40 weeks of period of gestation $(77.3 \%)$ followed by 36 to 37 weeks $(12.7 \%)$ and less than 35 weeks $(10 \%)$.
Table 1: Pregnancy outcomes amongst study population.

\begin{tabular}{|c|c|c|c|}
\hline \multicolumn{2}{|c|}{ Pregnancy outcomes } & Frequency & $\begin{array}{l}\text { Percent } \\
(\%)\end{array}$ \\
\hline \multirow{2}{*}{$\begin{array}{l}\text { Spontaneous } \\
\text { abortion }\end{array}$} & $\begin{array}{l}\mathrm{S} \text { and } \mathrm{E} \\
\text { done }\end{array}$ & 4 & 3.64 \\
\hline & $\begin{array}{l}\text { S and E not } \\
\text { done }\end{array}$ & 5 & 4.55 \\
\hline \multirow{3}{*}{$\begin{array}{l}\text { Term live } \\
\text { birth }\end{array}$} & $\begin{array}{l}\text { Cesarean } \\
\text { delivery }\end{array}$ & 35 & 31.82 \\
\hline & $\begin{array}{l}\text { Vacuum } \\
\text { assisted } \\
\text { vaginal } \\
\text { delivery }\end{array}$ & 2 & 1.82 \\
\hline & $\begin{array}{l}\text { Vaginal } \\
\text { delivery }\end{array}$ & 58 & 52.73 \\
\hline \multirow{3}{*}{$\begin{array}{l}\text { Preterm live } \\
\text { birth }\end{array}$} & $\begin{array}{l}\text { Cesarean } \\
\text { delivery }\end{array}$ & 1 & 0.91 \\
\hline & $\begin{array}{l}\text { Vacuum } \\
\text { assisted } \\
\text { vaginal } \\
\text { delivery }\end{array}$ & 0 & 0.00 \\
\hline & $\begin{array}{l}\text { Vaginal } \\
\text { delivery }\end{array}$ & 5 & 4.55 \\
\hline \multicolumn{2}{|l|}{ Total } & 110 & 100.00 \\
\hline
\end{tabular}

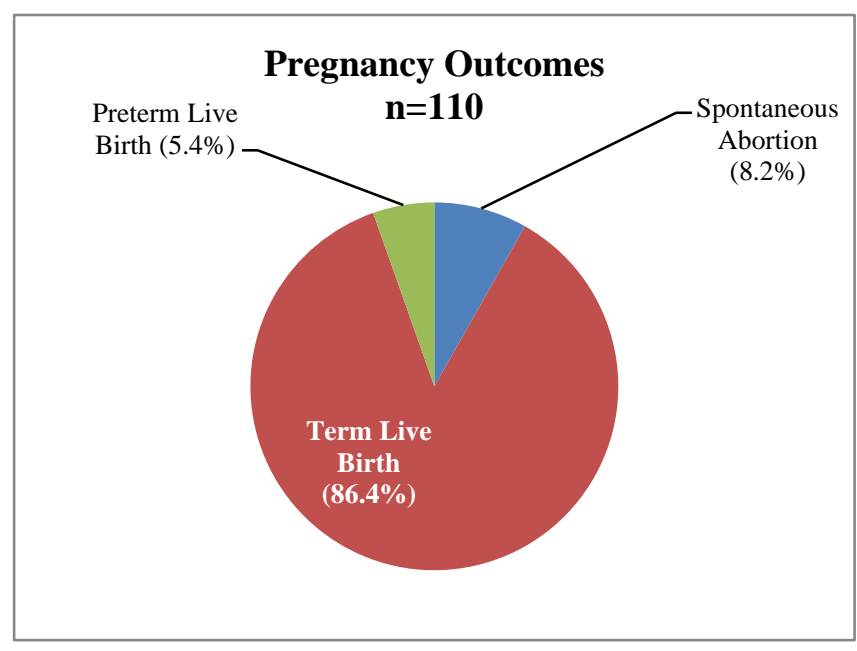

Figure 1: Pregnancy outcomes among study population.

The final outcomes were term live birth $(86.4 \%)$, spontaneous abortion (8.2\%), preterm delivery (5.4\%).

Most of the study population had babies birth weight of 2.6 to $3 \mathrm{~kg}(40 \%)$ followed by 3 to $3.5 \mathrm{~kg}(28.2 \%)$ and less than $2.5 \mathrm{~kg}(17.3 \%)$. NICU admission was observed in $16.4 \%$ of study population.

In the present study, gestational diabetes was the most common comorbidities observed amongst study population (20.9\%) followed by hypothyroidism (10\%), $\mathrm{h} / \mathrm{o}$ threatened abortion (7.3\%) and post LSCS (6.4\%). 
Foetal distress was the most common indication of cesarean delivery $(30.6 \%)$ followed by arrest of descent of head $(11.1 \%)$, breech and failed TOLAC $(8.3 \%)$ and failed induction and unfit for TOLAC $(5.6 \%)$.

Cesarean delivery (48.3\%) was the most common mode of delivery in subjects with history of suction and evacuation followed by vaginal delivery $(41.4 \%)$ and vacuum assisted vaginal delivery $(3.4 \%)$ and the difference was statistically significant $(\mathrm{p}=0.255)$

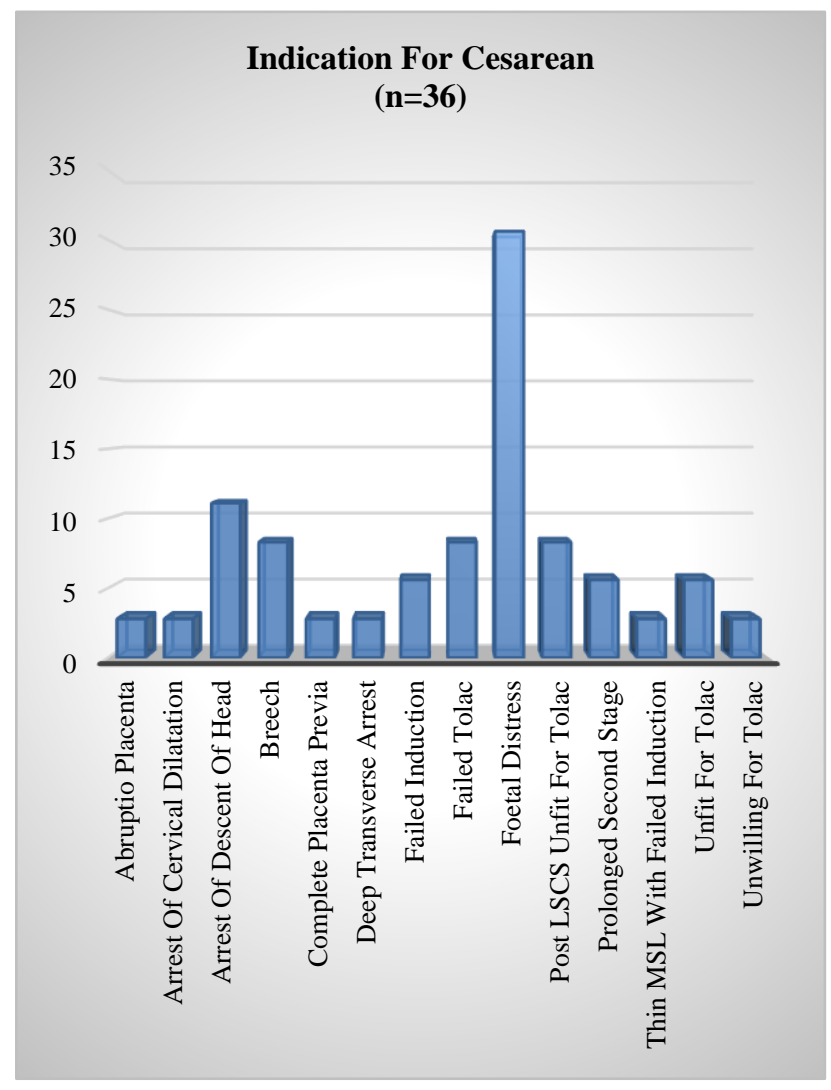

Figure 2: Indications for cesarean.

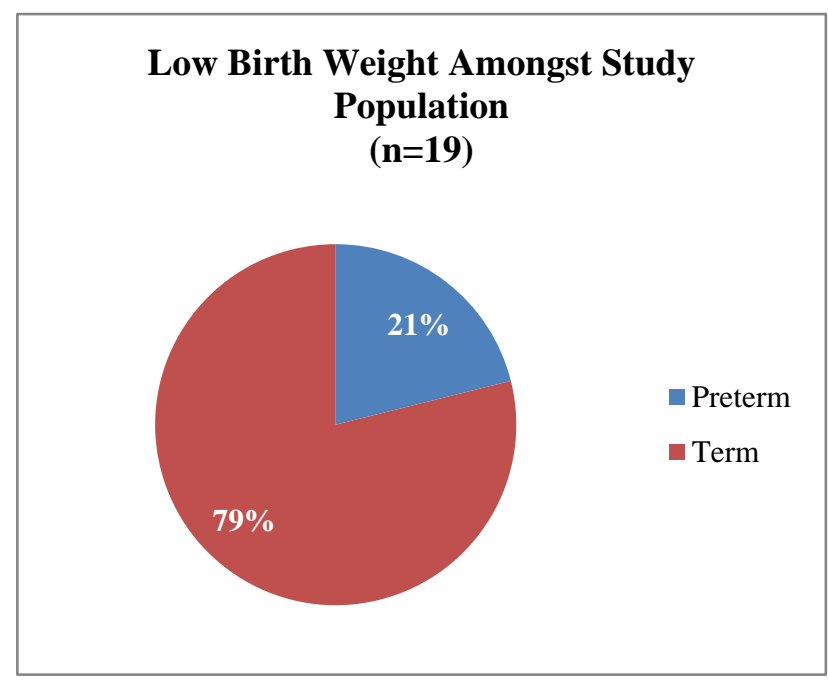

Figure 3: Low birth weight among study population.

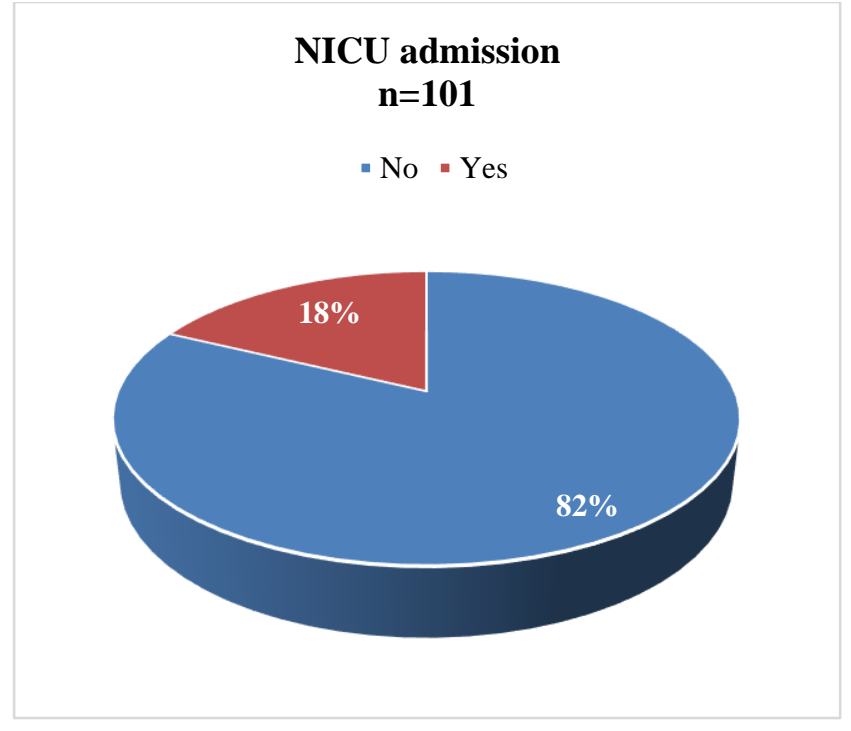

Figure 4: NICU admissions.

Table 2: Indication for cesarean amongst study population.

\begin{tabular}{|lll|}
\hline Indication for cesarean & $\begin{array}{l}\text { No. of } \\
\text { patients }\end{array}$ & $\begin{array}{l}\text { Percent } \\
(\%)\end{array}$ \\
\hline $\begin{array}{l}\text { Abruptio placenta } \\
\begin{array}{l}\text { Arrest of cervical } \\
\text { dilatation }\end{array}\end{array}$ & 1 & 2.8 \\
\hline $\begin{array}{l}\text { Arrest of descent of } \\
\text { head }\end{array}$ & 4 & 2.8 \\
\hline Breech & 3 & 11.1 \\
\hline $\begin{array}{l}\text { Complete placenta } \\
\text { previa }\end{array}$ & 1 & 8.3 \\
\hline Deep transverse arrest & 1 & 2.8 \\
\hline Failed induction & 2 & 2.8 \\
\hline Failed TOLAC & 3 & 5.6 \\
\hline Foetal distress & 11 & 8.3 \\
\hline $\begin{array}{l}\text { Post LSCS unfit for } \\
\text { TOLAC }\end{array}$ & 3 & 30.6 \\
\hline Prolonged second stage & 2 & 8.3 \\
\hline $\begin{array}{l}\text { Thin MSL with failed } \\
\text { induction }\end{array}$ & 1 & 5.6 \\
\hline Unfit for TOLAC & 2 & 2.8 \\
\hline Unwilling for TOLAC & 1 & 5.6 \\
\hline Total & 36 & 2.8 \\
\hline
\end{tabular}

Table 3: Low birth weight amongst study population.

\begin{tabular}{|lll|}
\hline Low birth weight & Frequency & Percent $(\%)$ \\
\hline Preterm & 4 & 21.1 \\
\hline Term & 15 & 78.9 \\
\hline Total & 19 & 100.0 \\
\hline
\end{tabular}

\section{DISCUSSION}

Our study was aimed to study pregnancy outcomes in 110 patients with history of previous spontaneous abortion preceding present pregnancy. Impact of previous 
spontaneous abortion on pregnancy has been studied. All patients were booked cases at this hospital and there was no loss to follow up in any of the cases.

In our study, in subjects with history of suction and evacuation, spontaneous abortion was observed in $8.2 \%$ of subjects. In the study by Bakshi et al $20.4 \%$ of subjects had spontaneous abortion. ${ }^{13}$

In the present study, most of the study population belongs to the age group of 25 to 30 years $(51.8 \%)$ followed by less than 25 years $(34.5 \%)$ and more than 30 years $(13.6 \%)$. Similarly in the study conducted by Abeysena et al it was observed that $89 \%$ were in the age group of 18 to 34 years. ${ }^{9,3}$ Study conducted by Adeniran et al reported that $434(72 \%)$ of these study population were aged $<35$ years while $169(28 \%)$ were aged $\geq 35$ years of age. History of suction and evacuation was most commonly observed in 25 to 30 years of age group $(41.1 \%)$ followed by less than 25 years $(34.5 \%)$ and more than 30 years $(24.1 \%)$ and the difference was statistically insignificant $(\mathrm{p}=0.050) .{ }^{14}$

In the present study, most of the study population were nullipara $(68.2 \%)$ followed by para $1(28.2 \%)$ and para 2 $(3.6 \%)$. This was in agreement with the study conducted by Abeysena et al, in which three hundred and forty-one (46.2\%) women were primiparous. ${ }^{15}$ Study conducted by Adeniran et al reported that $434(72 \%)$ of these study population were aged <35 years while 169 (28\%) were aged $\geq 35$ years of age. ${ }^{14}$

In the present study, in patients undergone spontaneous abortion, $\mathrm{S}$ and $\mathrm{E}$ done was done in $3.64 \%$, in term live birth patients. Cesarean delivery, vacuum assisted vaginal delivery and vaginal delivery was the mode of delivery in $31.82 \%, 1.8 \%$ and $52.73 \%$ respectively in term live births whereas in preterm live births, cesarean delivery, vacuum assisted vaginal delivery and vaginal delivery was the mode of delivery in $0.9 \%, 0 \%$ and $4.55 \%$ respectively. And the difference was statistically insignificant. These findings were in agreement with the study conducted by Agrawal et al in which mode of delivery was vaginal in 42 (70\%), instrumental delivery in $4(6.7 \%)$, and caesarian section was done in $14(23.3 \%)$ patients. Foetal distress was the most common indication of cesarean delivery $(30.6 \%)$ followed by arrest of descent of head (11.1\%), breech and failed TOLAC $(8.3 \%)$ and Failed Induction and unfit for TOLAC (5.6\%). ${ }^{16}$ In our study there was no still birth and there was one case of placenta previa.

In the study by Bhattacharya et al, they found that women with a previous miscarriage were prone to adverse perinatal outcomes in the next pregnancy in comparison with; a) women who had a successful first pregnancy; and b) women with no previous pregnancies. Women with a previous miscarriage were at higher risk of threatened miscarriage and preterm delivery. They were more likely to have interventions during labor and delivery and their babies tended to be small for their gestational age. ${ }^{17}$
In our study, in subjects with history of suction and evacuation preterm live birth was observed in $6.9 \%$. Previous studies on the influence of pregnancy loss on future risk of preterm birth are conflicting. There are relatively few studies with large sample sizes, and selection of the comparison groups and the parity of the women vary between studies. The risks of preterm birth and perinatal death were increased in women with a previous miscarriage and were markedly higher in cases of late miscarriage. Other complications that were inconsistently shown to be more common in these women include pre-eclampsia and bleeding in early pregnancy. ${ }^{18,19}$

In the present study, most of the study population had babies birth weight of 2.6 to $3 \mathrm{~kg}(40 \%)$ followed by 3 to $3.5 \mathrm{~kg}(28.2 \%)$ and less than $2.5 \mathrm{~kg}(17.3 \%)$. Term live birth $(86.1 \%)$ was the most common final outcome in subjects with history of suction and evacuation followed by preterm live birth $(6.9 \%)$ and spontaneous abortion $(6.9 \%)$ and the difference was statistically insignificant $(\mathrm{p}=0.891)$. In low-birth-weight babies, $78.9 \%$ babies were term and $21.1 \%$ were preterm. In our study, $17.3 \%$ babies were low birth weight out of which $78.9 \%$ babies were term and $21.1 \%$ were preterm. In the study by Thorn et al, only $5.8 \%$ of babies were low birth weight. ${ }^{20}$ In the study by Bakshi et al, $26 \%$ babies were low birth babies. ${ }^{13}$

\section{Limitation}

Only booked cases are taken in the study so with proper antenatal care some impact of abortion on next pregnancy neutralized by appropriate measures. Pregnancies conceived by ART procedures are not taken into the study. Pregnancies irrespective of gravidity were enrolled.

\section{CONCLUSION}

Patients with previous history of spontaneous abortion are associated with increased adverse pregnancy outcome however this was not observed in the present study. Spontaneous abortion observed in $8.2 \%$ of the patients. Most of the babies were term live birth (86.4\%) while preterm live birth occurred in $5.4 \%$. No stillborn was observed. There was one case of placenta previa and one case of abruption placentae was observed, however statistically insignificant in relation to history of spontaneous abortion. Cesarean delivery was the commonest mode of delivery in patients with history of suction and evacuation followed by vaginal delivery. Foetal distress was the most common indication of cesarean delivery $(30.6 \%)$ followed by arrest of descent of head $(11.1 \%)$. In our study there was no significant impact of spontaneous abortion in nulliparous women as compared to existing studies. Pregnancy outcomes are not adversely influenced by the history of one spontaneous abortion preceding present pregnancy in the present study probably due to timely booking of the patients and regular antenatal care provided to them in a tertiary care centre. 
Funding: No funding sources

Conflict of interest: None declared

Ethical approval: The study was approved by the Institutional Ethics Committee

\section{REFERENCES}

1. Morales C, Sánchez A, Bruguera J, Margarit E, Borrell A, Borobio V et al. Cytogenetic study of spontaneous abortions using semi-direct analysis of chorionic villi samples detects the broadest spectrum of chromosome abnormalities. Am J Med Genet Part A. 2008;146:66.

2. Janowicz-Grelewska A, Sieroszewski P. Prognostic significance of subchorionic hematoma for the course of pregnancy. Ginekol Polska. 2013;84:944-9.

3. Lemmers M, Verschoor MAC, Hooker AB, Opmeer BC, Limpens J, Huirne JAF. Dilatation and curettage increases the risk of subsequent preterm birth: A systematic review and meta-analysis. Hum Reprod. 2016;31(1):34-45.

4. Svare JA, Andersen LF, Langhoff-Roos J, Jensen ET, Bruun B, Lind I. The relationship between prior cervical conization, cervical microbial colonization and preterm premature rupture of the membranes. Eur J Obstet Gynecol Reprod Biol. 1992;47(1):41-5.

5. Zhou W, Sorensen HT, Olsen J. Induced abortion and low birthweight in the following pregnancy. Int $\mathrm{J}$ Epidemiol. 2000;29(1):100-6.

6. Watson LF, Rayner J, King J, Jolley D, Forster D. Intracervical procedures and the risk of subsequent very preterm birth: A case-control study. Acta Obstet Gynecol Scand. 2012;91(2):204-10.

7. Molin A. Risk of damage to the cervix by dilatation for first-trimester-induced abortion by suction aspiration. Gynecol Obstet Invest. 1993;35(3):152-4.

8. Ancel PY, Lelong N, Papiernik E, Saurel-Cubizolles MJ, Kaminski M. EUROPOP History of induced abortion as a risk factor for preterm birth in European countries: results of the EUROPOP survey. Hum Reprod. 2004;19(3):734-40.

9. Goldzieher JW, Benign BB. The treatment of threatened and recurrent abortion: a critical review. Am J Obstet Gynecol. 1958;75:1202-14.
10. Warburton D, Fraser FC. Spontaneous abortion risks in man: data from reproductive histories collected in a medical genetics' unit. Am J Hum Genet. 1964;16:125.

11. Poland BJ, Miller JR, Jones DC, Trimble BK. Reproductive counseling in patients who have had a spontaneous abortion. Am J Obstet Gynecol. 1977;127:685-91.

12. Naylor AF, Warburton D. Sequential analysis of spontaneous abortion. II. Collaborative study data show that gravidity determines a very substantial rise in risk. Fertil Steril. 1979;31:282-6.

13. Bakshi K, Rani TU, Kumar PP, Prabhakar G. Risk of adverse pregnancy outcomes after prior spontaneous abortion. Current Med Res Practice. 2015;5:258-61.

14. Adeniran AS, Fawole AA, Abdul IF, Adesina KT. Spontaneous abortions (miscarriages): Analysis of cases at a tertiary center in North Central Nigeria. J Med Trop. 2015;17:22-6.

15. Abeysena C. Risk factors for spontaneous abortion. J College Community Physicians of Sri Lanka. 2009;14(1):14-9.

16. Agrawal S, Agrawal V, Suhane R. Pregnancy outcome following spontaneous abortions. Int $\mathrm{J}$ Reprod Contracept Obstet Gynecol. 2015;4:1891-3.

17. Bhattacharya S, Townend J, Shetty A, Campbell D, Bhattacharya S. Does miscarriage in an initial pregnancy lead to adverse obstetric and perinatal outcomes in the next continuing pregnancy? BJOG. 2008;115:1623-9.

18. Eras JL, Saftlas AF, Triche E, Hsu CD, Risch HA, Bracken MB. Abortion and its effect on risk of preeclampsia and transient hypertension. Epidemiology. 2000;11(1):36-43.

19. Kashanian M, Akbarian AR, Baradaran H, Shabandoust SH. Pregnancy outcome following a previous spontaneous abortion (miscarriage). Gynecol Obstetric Investig. 2006;61(3):167-70.

20. Thorn DH. Spontaneous abortion and subsequent adverse birth outcomes. Am J obstet gvnecol. 1992;166:111-6.

Cite this article as: Dadheech SK, Bharadwaj MK, Menon BA. Pregnancy outcomes after spontaneous conception with previous spontaneous abortion preceding present pregnancy. Int J Reprod Contracept Obstet Gynecol 2021;10:3035-9. 